\title{
Iron Assessment in Elite Athletes
}

\author{
Paolo Borrione*, Claudia Battaglia and Alessandra Di Cagno \\ Department of Movement, Human and Health Sciences, University of Rome "Foro Italico", Piazza Lauro de Bosis, Rome, Italy
}

Corresponding author: Paolo Borrione, Internal Medicine, Department of Health Science, University of Rome "Foro Italico, Piazza Lauro de Bosis, Rome, Italy, Tel: +39-06-36733335; Fax: +39-06-36733344; E-mail: paolo.borrione@uniroma4.it

Rec date: 23 July 2014, Acc date: 25 July 2014, Pub date: 28 July 2014

Copyright: $\odot 2014$ Borrione P, et al. This is an open-access article distributed under the terms of the Creative Commons Attribution License, which permits unrestricted use, distribution, and reproduction in any medium, provided the original author and source are credited.

\begin{abstract}
Asymptomatic iron deficiency is frequently observed in competitive athletes and an impaired iron metabolism may lead to abnormal haemoglobin and myoglobin production limiting endurance capacity. Iron supplementation could improve blood biochemical measures and increases work capacity but the use of iron supplements should be a judicious choice based on a careful hematological evaluation since an unjustified treatment may lead to possible health risks as well as performance decrease. When considering competitive athletes, serum ferritine, commonly used to evaluate iron status, may not be always considered as an effective marker. Several studies suggested that hepcidin assessment may represent an alternative method to define the real necessity of iron supplementation in specific conditions such as in competitive athletes.
\end{abstract}

\section{Background}

With the exception of pregnant women, Competitive Athletes represents the group of subjects with the highest iron demand [1]. Within this population, iron requirements are increased by approximately $70 \%$ [2] since iron is an essential element for the formation of oxygen carrying proteins, namely hemoglobin and myoglobin, as well as for the activity of enzymes involved in energy production [3]. Thus, an impaired iron metabolism may lead to abnormal haemoglobin and myoglobin production limiting endurance capacity [4]. For this reason, in iron-deficient athletes, iron supplementation improves blood biochemical measures and increases work capacity, as evidenced by an increased oxygen uptake, reduced heart rate, and decreased lactate concentration during exercise [5]. Currently, no standardized guide-lines for iron administration are available and the decision of administrating iron to an athlete is mainly based on empiric recommendations or on performance enhancing hopes. With this regard, while the recommendation to pay particular attention in maintaining an adequate consumption of dietary iron would be always advisable, the use of iron supplements should be a judicious choice based on a careful hematological evaluation, mainly because of the possible health risks deriving from an unjustified treatment [6]. Indeed, the excess of iron has several deleterious consequences including the potential oxidative damage [7], as well as the risk of inducing hemochromatosis in individuals homozygous for the widespread C282Y polymorphism of the HFE gene [8].

When considering non-anemic subjects, the evaluation of the iron status, is usually based on the analysis of serum ferritin (SF) levels [9]. Values lower than $12 \mu \mathrm{g} / \mathrm{L}$, undoubtedly, represents a condition of iron deficiency requiring supplementation [9]. However, in competitive athletes, SF levels ranging between 12 and $30 \mu \mathrm{g} / \mathrm{L}$, reflecting an iron deficiency without anemia, are frequently observed. Within this SF range, which does not appear to affect athletic performance, the real usefulness of an iron supplementation is still matter of debate. In order to better evaluate the iron status, several biochemical parameters have been studied including serum iron, total iron binding capacity [10], transferrin saturation, transferrin receptor concentrations and transferrin receptor-ferritin ratio [11]. However, none of these variables has been identified as an effective marker for deciding when to start a justifiable iron supplementation in competitive athletes and the evaluation of SF levels still represent the golden standard for the study of iron metabolism. When considering the population composed by competitive athletes, it has to be taken into consideration that ferritin is an acute phase protein [12] and that exercise evokes an acute phase response, resulting in post exercise pro-inflammatory cytokines levels comparable to those seen during bacterial infection and/or inflammatory disorders [13]. Consequently, SF may not be always considered as an effective marker of the iron status in competitive athletes. To overcame this issue, several studies evaluated the possibility of investigating the iron status of athletes through the analysis of hepcidin levels $[4,14]$. Hepcidin is a circulating peptide hormone that regulates the entry of iron into plasma [15]. Hepcidin, primarily released by the liver, negatively regulates iron egress from intestinal cells and macrophages by altering the expression of the cellular iron exporter ferroportin [16]. Therefore, hepcidin acts as the key regulator of the total body iron, by modulating intestinal iron absorption, as well as iron availability for erythropoiesis by affecting the efficiency of macrophages mediated iron recycle [17]. These studies suggested that hepcidin assessment may represent an alternative method to define the real necessity of iron supplementation in specific conditions such as in competitive athletes. Moreover, these studies, confirmed that SF below $30 \mu \mathrm{g} / \mathrm{L}$ indicates an asymptomatic iron deficiency condition inhibiting hepcidin expression. Conversely, SF above $30 \mu \mathrm{g} / \mathrm{L}$ indicates adequate iron stores inducing the upregulation of hepcidin to prevent unnecessary iron absorption. The immediate clinical consequence of these findings relies in the conclusion that an iron supplementation would be useful when administered to athletes with SF below $30 \mu \mathrm{g} / \mathrm{L}$ in whom hepcidin levels are low to promote iron absorption. On the contrary, it would be not indicated in athletes with SF exceeding $30 \mu \mathrm{g} / \mathrm{L}$ in which hepcidin levels are consistent with sufficient body iron.

\section{Conclusion}

To contrast the alarming behaviour of athletes assuming iron supplements with a poor understanding of the purpose, it is necessary to provide accurate information [18]. Supplementation is not without consequences: the use of high doses of supplemental iron is often associated with gastrointestinal distress and constipation and a subsequent decline in the subject compliance and performance as well as with potential detrimental effects on both performance and health. Hepcidin assessment may represent an alternative method to verify the real necessity of iron supplementation in specific conditions in which 
SF evaluation may not reflect the real iron demand. It is well known that this analysis is not largely applicable, mainly because of the elevated costs and the diurnal variability of this hormone both in serum and urine [19]. Nevertheless, hepcidin may play an important diagnostic role in athletes referring symptoms that occur in overreaching and overtraining syndromes. This approach may reduce the possible contraindication and side effects linked to improper iron supplementation, especially in athletes to whom an incorrect supplementation may negatively affect the performance rather than improve it.

\section{References}

1. Peeling P, Dawson B, Goodman C, Landers G, Trinder D (2008) Athletic induced iron deficiency: new insights into the role of inflammation, cytokines and hormones. Eur J Appl Physiol 103: 381-391.

2. Whiting SJ, Barabash WA (2006) Dietary Reference Intakes for the micronutrients: considerations for physical activity. Appl Physiol Nutr Metab 31: 80-85.

3. Volpe S.(2006) Vitamins, minerals, and exercise. In: Dunford M, ed. Sports Nutrition: A Practice Manual for Professionals. Chicago, IL: American Dietetic Association: 61-63.

4. Borrione P, Spaccamiglio A, Rizzo M, Termine A, Chierto E, et al. (2011) Urinary hepcidin identifies a serum ferritin cut-off for iron supplementation in young athletes: a pilot study. J Biol Regul Homeost Agents 25: 427-434.

5. Lukaski HC (2004) Vitamin and mineral status: effects on physical performance. Nutrition 20: 632-644.

6. Dascombe BJ, Karunaratna M, Cartoon J, Fergie B, Goodman C (2010) Nutritional supplementation habits and perceptions of elite athletes within a state-based sporting institute. J Sci Med Sport 13: 274-280.

7. Jenkins RR, Krause K, Schofield LS (1993) Influence of exercise on clearance of oxidant stress products and loosely bound iron. Med Sci Sports Exerc 25: 213-217.

8. European Association For The Study Of The Liver (2010) EASL clinical practice guidelines for HFE hemochromatosis. J Hepatol 53: 3-22.
9. Garza D, Shrier I, Kohl HW 3rd, Ford P, Brown M, et al. (1997) The clinical value of serum ferritin tests in endurance athletes. Clin J Sport Med 7: 46-53.

10. Karamizrak SO, IÅŸlegen C, Varol SR, TaÅŸkiran Y, Yaman C, et al. (1996) Evaluation of iron metabolism indices and their relation with physical work capacity in athletes. Br J Sports Med 30: 15-19.

11. Samuleson G, Lönnerdal B, Kempe B, Elverby JE, Bratteby LE (2000). A follow up study of serum ferritin and trasferrin receptor concentrations in Swedish adolescents at age 17 and 15. Acta Paediatr 89: 1162-1168.

12. Kalantar-Zadeh K, Rodriguez RA, Humphreys MH (2004) Association between serum ferritin and measures of inflammation, nutrition and iron in haemodialysis patients. Nephrol Dial Transplant 19: 141-149.

13. Cooper DM, Radom-Aizik S, Schwindt C, Zaldivar F Jr (2007) Dangerous exercise: lessons learned from dysregulated inflammatory responses to physical activity. J Appl Physiol (1985) 103: 700-709.

14. Ziemann E, Kasprowicz K, Kasperska A, Zembro ^,-Lacny A, Antosiewicz J, et al. (2013) Do high blood hepcidin concentrations contribute to low ferritin levels in young tennis players at the end of tournament season? J Sports Sci Med 12: 249-258.

15. Ganz T1, Nemeth E (2011) Hepcidin and disorders of iron metabolism. Annu Rev Med 62: 347-360.

16. Piperno A, Mariani R, Trombini P, Girelli D (2009) Hepcidin modulation in human diseases: from research to clinic. World J Gastroenterol 15: 538-551.

17. Fleming MD (2008) The regulation of hepcidin and its effects on systemic and cellular iron metabolism. Hematology Am Soc Hematol Educ Program .

18. Petróczi A, Naughton DP, Mazanov J, Holloway A, Bingham J (2007) Performance enhancement with supplements: incongruence between rationale and practice. J Int Soc Sports Nutr 4: 19.

19. Kroot JJ, Hendriks IC, Laarakkers CM. Klaver SM. Kemna EH, et al. (2009) (Pre)analytical imprecision, between-subject variability. and daily variations in serum and urine hepcidin: implications for clinical studies. Annal Biochem 389:124-129. 